\title{
The energy expenditure of people with spinal cord injury whilst walking compared to an able-bodied population
}

\begin{tabular}{|c|c|}
\hline \multicolumn{2}{|c|}{$\begin{array}{l}\text { Authors: } \\
\text { Jana Vosloo }^{1} \\
\text { M. Veronica Ntsiea } \\
\text { Piet Becker }\end{array}$} \\
\hline \multicolumn{2}{|c|}{$\begin{array}{l}\text { Affiliations: } \\
{ }^{1} \text { Department of } \\
\text { Physiotherapy, University of } \\
\text { the Witwatersrand, South } \\
\text { Africa }\end{array}$} \\
\hline \multicolumn{2}{|c|}{$\begin{array}{l}{ }^{2} \text { Biostatistics Unit, South } \\
\text { African Medical Research } \\
\text { Council, South Africa }\end{array}$} \\
\hline \multicolumn{2}{|c|}{$\begin{array}{l}\text { Corresponding author: } \\
\text { Veronica Ntsiea, veronica. } \\
\text { ntsiea@wits.ac.za }\end{array}$} \\
\hline \multicolumn{2}{|c|}{$\begin{array}{l}\text { Dates: } \\
\text { Received: } 14 \text { Apr. } 2015 \\
\text { Accepted: } 01 \text { Dec. } 2015 \\
\text { Published: } 31 \text { Mar. } 2016\end{array}$} \\
\hline \multicolumn{2}{|c|}{$\begin{array}{l}\text { How to cite this article: } \\
\text { Vosloo, J., Ntsiea, M.V. \& } \\
\text { Becker, P., 2016, 'The energy } \\
\text { expenditure of people with } \\
\text { spinal cord injury whilst } \\
\text { walking compared to an } \\
\text { able-bodied population', } \\
\text { South African Journal of } \\
\text { Physiotherapy 72(1), a255. } \\
\text { http://dx.doi.org/10.4102/ } \\
\text { sajp.v72i1.255 }\end{array}$} \\
\hline \multicolumn{2}{|c|}{$\begin{array}{l}\text { Copyright: } \\
\text { (c) 2016. The Authors. } \\
\text { Licensee: AOSIS. This work is } \\
\text { licensed under the Creative } \\
\text { Commons Attribution } \\
\text { License. }\end{array}$} \\
\hline \multicolumn{2}{|l|}{ Read online: } \\
\hline 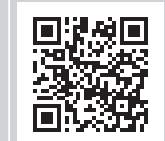 & $\begin{array}{l}\text { Scan this QR } \\
\text { code with your } \\
\text { smart phone or } \\
\text { mobile device } \\
\text { to read online. }\end{array}$ \\
\hline
\end{tabular}

Background: In the field of spinal cord injury (SCI) research there is an emphasis on the ability to ambulate.

Purpose: To determine the ambulation energy expenditure (EE) and factors that affect ambulation EE in SCI participants compared to able-bodied participants.

Methods: This was a cross-sectional study. Participants were recruited from seven SCI rehabilitation units within the Johannesburg area. The following were used: demographic questionnaire to capture participants' characteristics, modified Ashworth scale for spasticity; goniometer for range of movement (ROM); American Spinal Injury Association (ASIA) scale for patient classification; accelerometer for EE and the six-minute walk test (6MWT) for endurance. Characteristics of the study participants were summarised using descriptive statistics. Data were analysed as follows: two-sample $t$-test for comparison between the able-bodied and SCI sample and Pearson product moment correlations for relationship between identified factors and EE.

Results: Participants comprised 45 in the SCI group and 21 in the able-bodied group. The mean energy expenditure per metre $(\mathrm{EE} / \mathrm{m})$ for the SCI participants was $0.33( \pm 0.29)$ calories compared to $0.08( \pm 0.02)$ calories for the able-bodied participants. A decrease in walking velocity resulted in an increase in EE. For SCI participants, every decrease in degree of hip flexion ROM resulted in a 0.003 increase in $\mathrm{EE} / \mathrm{m}$ walked. A unit decrease in velocity resulted in an increase of 0.41 in $\mathrm{EE} / \mathrm{m}$ walked. Energy expenditure per metre decreased from ASIA A to ASIA D. Crutch walking utilised 0.34 calories per metre less energy than walking frames $(p=0.03)$.

Conclusion: Based on this study's findings, factors to consider in order to maximise energy efficiency whilst walking are maintaining hip flexion ROM and optimising velocity of walking.

\section{Introduction}

In the field of spinal cord injury (SCI) research there is an emphasis on ability to ambulate as a functional outcome (Jackson et al. 2008). Walking for routine activities of daily living (ADLs) requires ability to cover more than $250 \mathrm{~m}$ and to spend on average at least $10 \mathrm{~min}$ walking (Ulkar et al. 2003).

In people with SCI, gait patterns are significantly altered because of decreased strength, endurance, proprioception and spasticity (Jackson et al. 2008). These impairments may also result in the use of orthotic devices which can increase energy demands (Field-Fote \& Fluet 2001). When energy expenditure (EE) during orthotic-assisted gait is compared to able-bodied individuals, as expected, the energy cost is far higher during orthotic gait (Kawashima et al. 2006). Another factor that would impact walking efficiency is the level of neurological impairment. High levels of SCI lesions result in high physiological intensity when walking (Kawashima et al. 2006).

The excess EE for ambulation and the burden on particularly the upper limbs present a challenge in achieving functional walking. It is therefore vital to explore options to reduce the excess physiological load (Kawashima et al. 2006). The following factors have been found to affect ambulation for people with a variety of medical conditions, including SCI: being overweight (Yamakawa et al. 2004), increased age (Scivoletto et al. 2003), spasticity (Mahoney et al. 2007), pain (Richards et al. 2004), range of movement (ROM) (Kawashima et al. 2006), level of lesion (Kawashima et al. 2005), assistive devices (Kawashima et al. 2006), extent of treatment (Scivoletto et al. 2008) and duration since the injury (Kirshblum et al. 2004). Even though these factors were established using a variety of medical conditions, all of these factors are also applicable to patients with SCI. Expenditure of a considerable amount of metabolic energy is also required when walking (Kuo 2007). 
There is a dearth of literature on the effect of the abovementioned factors on EE whilst walking for people with SCI when compared to able-bodied people. The purpose of this study was to determine ambulation EE and also establish factors that affect ambulation EE in SCI participants compared to able-bodied participants. Having evidence of walking EE for individuals with SCI compared to an ablebodied population would enable therapists to draw conclusions regarding the discrepancies that may exist and quantify these discrepancies.

\section{Methods}

This was a cross-sectional study using a questionnaire, direct observations and physical assessments. Ethical clearance was applied for and obtained from the Committee for Research on Human Subjects of the University of the Witwatersrand (clearance number: M110944). The required sample size was determined as follows: from the pilot study performed with 10 participants in each group, the able-bodied participants' mean EE had a standard deviation of \pm 0.018 calories per metre $(\mathrm{cal} / \mathrm{m})$. The standard deviation for the able- bodied participants was used because they were expected to have a relatively lower EE than SCI participants and thus the sample size requirements would be relatively higher than when using high scores for the SCI participants. Using this standard deviation, a sample size of at least 28 SCI participants and at least 14 able-bodied participants had $90 \%$ power to detect change in EE within a group. A standard deviation of $0.018 \mathrm{cal} / \mathrm{m}$ was used and testing was two-sided at the 0.05 level of significance.

Participants for the study were recruited from seven conveniently selected SCI rehabilitation units (five private and two government) within the Johannesburg area of South Africa. These facilities were contacted on a weekly basis to enquire about suitable participants. A process of consecutive sampling was used until the required number of participants was reached. Recruitment for the able-bodied group was carried out by requesting therapists and other staff members, family and friends meeting the criteria to participate. Participants with SCI had to meet the following eligibility criteria:

- was ambulatory prior to SCI (to exclude those whose ambulation limitations were not as a result of SCI)

- has a complete thoracic level 10 and below or incomplete lesions at any spinal level

- comprehend and follow instructions

- walk $10 \mathrm{~m}$ unassisted (with or without walking aids and orthotics).

Able-bodied participants were included if they were comparable in age, gender and body mass index (BMI) to participants with SCI. The researcher provided potential participants with information, clearly stating the aims of the study and what was expected if they chose to participate. Informed consent was sought from those who were willing to participate in the study.

\section{Instruments used during the data collection process}

A questionnaire was developed which captured the following information about the SCI participants: gender, age, date of SCI, use of orthotics and walking aids for mobility, extent of mobility (whether they walk therapeutically, walk indoors, walk outdoors, walk at work and walk in the community), duration since SCI, inpatient and outpatient therapy, therapy hours per day and duration of rehabilitation hospital stay. Other items that could influence EE such as BMI, level of the lesion, presence of pain and extent of rehabilitation were also included. The matched able-bodied participants only filled in age, gender and mobility. Their height and weight were measured and used to calculate their BMI. The BMI and EE were also recorded on the questionnaire sheet. Content validity of this questionnaire was established by asking therapists who work in the SCI rehabilitation units to assist with identification of factors that could influence EE of SCI participants whilst walking. This was done by asking them to comment on the questionnaire and via individual interviews.

Each SCI participant had the American Spinal Injury Association (ASIA) impairment scale assessment to classify the severity of their SCI (ASIA 2002; Lammertse et al. 2007). The researcher assessed both motor and sensory scores with the ASIA impairment scale to establish the level of the spinal cord lesion. The ASIA classification (ASIA 2002) is as follows:

- ASIA A: complete injury where no sensory or motor function is preserved in sacral segments S4-S5

- ASIA B: incomplete injury where sensory but not motor function is preserved below the neurologic level and extends through sacral segments S4-S5

- ASIA C: incomplete injury where motor function is preserved below the neurological level, and most key muscles below the neurologic level have muscle grade less than three (active full-range movement against gravity)

- ASIA D: incomplete injury where motor function is preserved below the neurological level, and most key muscles below the neurologic level have muscle grade greater than or equal to three

- ASIA E: normal sensory and motor functions.

Height and weight measurements were done for all participants in order to calculate BMI. The height measurement was done in supine on the plinth with legs and trunk straightened and ankles in a neutral position (plantargrade). No shoes were worn during this measurement. Arms were positioned by the participant's sides. A mark was made on the surface at the top of the head and between the bases of the heels with the ankles in neutral. The participant then moved aside to allow measurement of the two points to establish the height. Measurements were done using a measuring tape. Prior to weight measurement the SECA 813 scale was calibrated by using a $3 \mathrm{~kg}$ dumbbell weight before each weight measurement was performed. The weight measurement was done by 
stepping onto the scale, which was positioned within the parallel bars. The participants were allowed to use the bars to climb onto the scale and to steady themselves until balanced. If the participant was dependent on orthotics to maintain balance, the assistive devices were weighed afterwards and the weight subtracted from the weight of initial measurement. If accurate weight measurement was difficult because participants were unable to statically stand without external support, it was noted on the demographic questionnaire. Weight was measured to the nearest $0.1 \mathrm{~kg}$ using the SECA 813 digital scale (Van Cauwenberghe et al. 2011). A BMI range of $18.5 \mathrm{~kg} / \mathrm{m}^{2}-24.9 \mathrm{~kg} / \mathrm{m}^{2}$ was considered normal (WHO 2000).

The amount of energy expended whilst performing the walking assessment was evaluated using an RT3 triaxial accelerometer (Hale et al. 2007; Hendrick et al. 2010). The RT3 provides data measured in 'activity units' and can be converted to estimate $\mathrm{EE}$ in total calories or metabolic equivalent (METS) (Hale et al. 2007). For the purposes of this study, the evaluation of the most discrete movements that would influence the EE over a set distance was important. Data were recorded in one-second intervals. The walking assessment was performed with participants walking at a comfortable self-selected speed along the well indicated $10 \mathrm{~m}$ line, which was marked at $2.5 \mathrm{~m}$ intervals.

The six-minute walk test (6MWT) was used to establish endurance (Stuart, Holland \& New 2009). No numeric adjustments in scoring were made for the use of walking devices, orthotics or pharmaceutical anti-spasmodics, but the use of these products were recorded in the demographic questionnaire. A Polar heart rate monitor was used to measure baseline and end of walking pulse rate as an indicator of cardiac regulation and physiological cost of gait (Arazpour et al. 2012). The Modified Ashworth Scale (MAS) was used to measure the intensity of spasticity where applicable (Kakebeeke et al. 2002). For the muscle which primarily performs flexion at a joint, the limb was positioned in maximal flexion and moved into maximal extension over one second. The opposite occurred when a muscle of primary extension was tested. A goniometer was used to measure the ROM for the lower limbs (EriksHoogland et al. 2011).

Categorical data were summarised as numbers and percentages. Continuous data were summarised as means and standard deviations. Data were analysed for comparison between the able-bodied and SCI sample using the twosample $t$-test. Fisher's exact and chi-squared tests were used to establish the relationship between categorical variables. Pearson's product moment correlations were used to establish the relationship between identified factors and ambulatory EE. Scheffé comparison was used to analyse the differences in EE whilst walking with different assistive devices. Multivariate stepwise regressions were performed to establish factors which had an influence on ambulatory EE. The factors which had significant relationships with EE from a univariate analysis were included in the stepwise multivariable regression. Factors which did not remain significant were removed.

\section{Results}

The data collection period was January to November 2012. The sample consisted of 45 SCI and 21 able-bodied participants. The mean age for the SCI and able-bodied participants was $38.9( \pm 13.6)$ and $34.7( \pm 9.7)$ years respectively. There were more men in both the SCI and ablebodied groups ( $80 \%$ and $76.2 \%$ respectively). The mean BMI was $23.9( \pm 5.1) \mathrm{kg} / \mathrm{m}^{2}$ for the SCI and $23.8( \pm 4.4) \mathrm{kg} / \mathrm{m}^{2}$ for the able-bodied participants. The differences between age, gender and BMI of both groups were not statistically significant. Twenty percent of the SCI participants had increased tone bilaterally and throughout ROM.

Of the participants, $46.6 \%(n=21)$ had an injury above T10 which was incomplete and therefore still enabled them to walk. Thoracic spinal cord injuries, T10-T12, were observed in $26.7 \%(n=12)$ of participants. Lumbar spine injuries, L1-L5, also represented $26.7 \%$ of the SCI group. With regard to ASIA classification scores (Table 1), the mean motor and sensory scores are highest for ASIA D and progressively decrease with each category so that scores are lowest for ASIA A.

Most of the participants (38\%) reported less than 6 months since SCI, 51.1\% received outpatient therapy after discharge from an inpatient facility, $38 \%$ received 4 hours of therapy per day and 55\% had an inpatient stay of more than 10 weeks (Table 2). SCI participants who did not have outpatient rehabilitation presented with 0.52 more EE than those who received outpatient therapy $(p=0.002)$.

Results pertaining to EE, distance, velocity and pulse before and after performing the 6MWT are shown in Table 3. Energy expenditure for the able-bodied participants was higher than for SCI participants $(p<0.001)$; however, EE/m was much higher for SCI participants than for able-bodied participants $(p<0.001)$.

Mean EE/m was higher for the SCI participants older than 50 years $(0.40 \mathrm{cal} / \mathrm{m})$ and lower for those younger than 50 years $(0.30 \mathrm{cal} / \mathrm{m})$. Men had higher mean EE than women in both groups: men with SCI used $0.34 \mathrm{cal} / \mathrm{m}$ and ablebodied men $0.08 \mathrm{cal} / \mathrm{m}$ compared to $0.27 \mathrm{cal} / \mathrm{m}$ for women with SCI and $0.07 \mathrm{cal} / \mathrm{m}$ for able-bodied women. However, walking distance was greater for men in both groups

TABLE 1: American Spinal Injury Association classification motor and sensory scores.

\begin{tabular}{|c|c|c|c|c|c|c|c|c|}
\hline \multirow[t]{2}{*}{ ASIA } & \multicolumn{2}{|c|}{ A } & \multicolumn{2}{|c|}{ B } & \multicolumn{2}{|c|}{ C } & \multicolumn{2}{|c|}{ D } \\
\hline & $n$ & $\%$ & $n$ & $\%$ & $n$ & $\%$ & $n$ & $\%$ \\
\hline $\begin{array}{l}\text { Number of } \\
\text { participants }\end{array}$ & 6 & 13 & 1 & 2 & 12 & 27 & 26 & 58 \\
\hline Mean sensory score & 147.3 & - & 175 & - & 179.5 & - & 183.8 & - \\
\hline Mean motor score & 54.8 & - & 65 & - & 68.4 & - & 74.1 & - \\
\hline
\end{tabular}


TABLE 2: Duration since spinal cord injury and extent of treatment after spinal cord injury.

\begin{tabular}{|c|c|c|c|}
\hline Patient detail & Factor & $n$ & $\%$ \\
\hline \multirow[t]{6}{*}{ Duration since $\mathrm{SCl}$} & $<6$ months & 17 & 38 \\
\hline & $\geq 6$ months -1 year & 10 & 22.2 \\
\hline & $>1-2$ years & 6 & 13.3 \\
\hline & $>2$ years -5 years & 5 & 11 \\
\hline & $>5$ years -10 years & 6 & 13.3 \\
\hline & $>10$ years & 1 & 2.2 \\
\hline \multirow{3}{*}{$\begin{array}{l}\text { Inpatient and } \\
\text { outpatient therapy }\end{array}$} & No therapy after discharge as inpatient & 3 & 6.7 \\
\hline & $\begin{array}{l}\text { Outpatient therapy only at time of data } \\
\text { collection }\end{array}$ & 23 & 51.1 \\
\hline & Still in inpatient rehabilitation & 19 & 42.2 \\
\hline \multirow{5}{*}{$\begin{array}{l}\text { Therapy hours per } \\
\text { day }\end{array}$} & 1 hour per day & 1 & 2 \\
\hline & 2 hours per day & 4 & 9 \\
\hline & 3 hours per day & 13 & 29 \\
\hline & 4 hours per day & 17 & 38 \\
\hline & $>4$ hours per day & 10 & 22 \\
\hline \multirow{6}{*}{$\begin{array}{l}\text { Duration of } \\
\text { rehabilitation } \\
\text { hospital stay }\end{array}$} & $<2$ weeks & 0 & 0 \\
\hline & 2-4 weeks & 8 & 18 \\
\hline & $>4-6$ weeks & 4 & 9 \\
\hline & $>6-8$ weeks & 5 & 11 \\
\hline & > 8-10 weeks & 3 & 7 \\
\hline & $>10$ weeks & 25 & 55 \\
\hline
\end{tabular}

$n=45$.

$\mathrm{SCl}$, spinal cord injury.

TABLE 3: Energy expenditure.

\begin{tabular}{|c|c|c|c|c|c|}
\hline Variables & $\begin{array}{c}\mathrm{SCl} \\
\text { mean } \\
( \pm \text { s.d. })\end{array}$ & $\begin{array}{c}\text { Able-bodied } \\
\text { mean } \\
( \pm \text { s.d.) }\end{array}$ & $\begin{array}{l}\text { Mean difference } \\
\text { between SCl } \\
\text { and able-bodied }\end{array}$ & $p$ value & $\begin{array}{l}95 \% \text { confidence } \\
\text { interval for } \\
\text { difference } \\
\text { between groups }\end{array}$ \\
\hline \multirow[t]{2}{*}{ EE (cal) } & 19.6 & 30.8 & 11.2 & $<0.001$ & $-16.50 ;-5.96$ \\
\hline & 10.1 & 9.8 & & & \\
\hline \multirow[t]{2}{*}{$\mathrm{EE} / \mathrm{m}$} & 0.33 & 0.08 & 0.25 & $<0.001$ & $0.12 ; 0.37$ \\
\hline & 0.29 & 0.02 & & & \\
\hline \multirow[t]{2}{*}{ Distance $(\mathrm{m})$} & 114.1 & 388.7 & 274.6 & $<0.001$ & -324.48 \\
\hline & 104.4 & 67.2 & & & -224.84 \\
\hline \multirow{2}{*}{$\begin{array}{l}\text { Velocity } \\
(\mathrm{m} / \mathrm{s})\end{array}$} & 0.32 & 1.1 & 0.76 & $<0.001$ & $-0.90 ;-0.63$ \\
\hline & 0.29 & 0.19 & & & \\
\hline \multirow{2}{*}{$\begin{array}{l}\text { Pulse before } \\
\text { walking } \\
\text { (bpm) }\end{array}$} & 76.6 & 77.9 & 1.3 & 0.71 & $-7.88 ; 5.41$ \\
\hline & 13.6 & 9.9 & & & \\
\hline \multirow{2}{*}{$\begin{array}{l}\text { Pulse after } \\
\text { walking } \\
\text { (bpm) }\end{array}$} & 106.4 & 87.7 & 18.7 & $<0.001$ & $10.29 ; 27.27$ \\
\hline & 17.7 & 11.8 & & & \\
\hline
\end{tabular}

$\mathrm{SCl}, n=45$; Able-bodied, $n=21$.

$\mathrm{SCl}$, spinal cord injury; $\mathrm{SD}$, standard deviation; $\mathrm{EE}$, energy expenditure; cal, calorie; $\mathrm{EE} / \mathrm{m}$ energy expenditure per metre; $\mathrm{m}$, metres; $\mathrm{m} / \mathrm{s}$, metres per second; $\mathrm{bpm}$, beats per minute.

(SCI participants: $121.9 \mathrm{~m}$ for men and $82.7 \mathrm{~m}$ for women; able-bodied participants: $395 \mathrm{~m}$ for men and $368.5 \mathrm{~m}$ for women). The EE/m increased with an increase in BMI for both SCI and able-bodied participants (SCI participants: $0.15 \mathrm{cal} / \mathrm{m}$ at a BMI of $16 \mathrm{~kg} / \mathrm{m}^{2}-16.9 \mathrm{~kg} / \mathrm{m}^{2}$, reaching $0.39 \mathrm{cal} / \mathrm{m}$ at a BMI of $30 \mathrm{~kg} / \mathrm{m}^{2}-35 \mathrm{~kg} / \mathrm{m}^{2}$; able-bodied participants: $0.04 \mathrm{cal} / \mathrm{m}$ at a BMI of $17 \mathrm{~kg} / \mathrm{m}^{2}-18.49 \mathrm{~kg} / \mathrm{m}^{2}$, reaching $0.11 \mathrm{cal} / \mathrm{m}$ at a BMI of $\left.30 \mathrm{~kg} / \mathrm{m}^{2}-35 \mathrm{~kg} / \mathrm{m}^{2}\right)$. Mean $\mathrm{EE} / \mathrm{m}$ was highest for ASIA A $(0.71 \mathrm{cal} / \mathrm{m})$ and decreased towards ASIA D (C: $0.29 \mathrm{cal} / \mathrm{m}$; D: $0.26 \mathrm{cal} / \mathrm{m})$ - with the exception of ASIA B $(n=1): 0.13 \mathrm{cal} / \mathrm{m}$.

The mean EE was the highest for SCI participants walking with a walking frame and an orthotic $(0.54 \mathrm{cal} / \mathrm{m})$, followed by walking frame only $(0.52 \mathrm{cal} / \mathrm{m})$ and crutches only $(0.18 \mathrm{cal} / \mathrm{m})$. It was the lowest for SCI participants walking with crutch and orthotic or without a crutch or with orthotic only $(0.16 \mathrm{cal} / \mathrm{m}$ for all these categories). Energy expenditure per metre of walking with crutches compared to a walking frame was significantly different $(p=0.03)$ and EE was $0.34 \mathrm{cal} / \mathrm{m}$ less for walking with crutches.

Results of the association between age, gender, BMI, velocity, pulse, ASIA classification, spasticity, length of rehabilitation stay, ROM and EE/m walked are shown in Table 4 . There was a statistically significant association between an increase in walking velocity, hip flexion, hip extension and knee flexion ROM and decrease in the $\mathrm{EE} / \mathrm{m}$ of walking.

Table 5 presents the multivariate stepwise regression analysis results for factors which had an influence on EE during walking. An inverse relationship was identified between EE/m walked and hip flexion ROM; for every degree decrease in hip flexion ROM there was a 0.003 increase in $\mathrm{EE} / \mathrm{m}$ walked $(p=0.01)$. A unit decrease in velocity resulted in an increase of 0.41 in $\mathrm{EE} / \mathrm{m}$ walked. ASIA A was used as the reference point in this analysis between ASIA classification and EE/m whilst walking. SCI participants with ASIA B, C and D had significantly less EE than those with ASIA A ( $p$ values are $0.05,0.01$ and 0.01 respectively).

TABLE 4: The correlation of age, gender, body mass index, velocity, pulse, American Spinal Injury Association (motor and sensory scores), spasticity, length of rehabilitation stay, range of movement with energy expenditure per metre respectively.

\begin{tabular}{lcc}
\hline Variable & Correlation coefficient & $p$ value \\
\hline Age & 0.20 & 0.30 \\
Gender - male $\dagger$ & -0.10 & 0.51 \\
BMI & 0.01 & 0.97 \\
Velocity & -0.60 & $<0.001$ \\
Pulse after & 0.20 & 0.13 \\
Motor score (ASIA) & -0.30 & 0.08 \\
Sensory score (ASIA) & -0.30 & 0.02 \\
Spasticity - MAS for hip flexion & -0.02 & 0.91 \\
Spasticity-MAS for hip extension & -0.02 & 0.87 \\
Length of rehab stay & -0.10 & 0.56 \\
Hip flexion ROM & -0.55 & $<.001$ \\
Hip extension ROM & -0.30 & 0.04 \\
Knee flexion ROM & -0.30 & 0.03 \\
Dorsiflexion ROM & -0.01 & 0.93 \\
Plantarflexion ROM & 0.20 & 0.23 \\
\hline
\end{tabular}

BMI, body mass index; ASIA, American Spinal Injury Association; MAS, Modified Ashworth Scale; ROM, range of movement.

$\dagger$, Point biserial correlation.

TABLE 5: Multivariable analysis results for factors which had an influence on energy expenditure during walking.

\begin{tabular}{lccccc}
\hline Variable & $\begin{array}{c}\text { Regression } \\
\text { coefficient } \uparrow\end{array}$ & $\begin{array}{c}\text { Standard } \\
\text { error }\end{array}$ & $\boldsymbol{t}$-test & $\boldsymbol{p}$ value & $\begin{array}{c}95 \% \text { confidence } \\
\text { interval }\end{array}$ \\
\hline ROM: Hip flexion & -0.003 & 0.002 & -1.67 & 0.01 & $-0.006:-0.001$ \\
Velocity (m/s) & -0.41 & 0.15 & -2.80 & 0.01 & $-0.70:-0.11$ \\
ASIA scores: & - & - & - & - & - \\
ASIA B & -0.55 & 0.27 & -2.07 & 0.05 & $-1.10:-0.01$ \\
ASIA C & -0.38 & 0.13 & -2.87 & 0.01 & $-0.64:-0.11$ \\
ASIA D & -0.35 & 0.13 & -2.69 & 0.01 & $-0.61:-0.09$ \\
\hline
\end{tabular}

Note: Reference for ASIA scores is ASIA A classification.

ROM, range of movement; ASIA, American Spinal Injury Association.

$\dagger$, Effect with reference to baseline. 


\section{Discussion}

The mean age of the SCI participants was 38.9 years, which is generally younger than those in international studies (Kennedy et al. 2003; McKinley et al. 2007; Scivoletto et al. 2003). In a study by Joseph et al. (2015) on SCI which was conducted in Cape Town, the mean age of the participants was 33.5 years. The low average range between the current study and Joseph's study in relation to other international studies may be as a result of the general lower life expectancy in South Africa compared to developed countries (World Bank 2009). Despite a worldwide increase in life expectancy for people living with SCI on the basis of technological and medical advances (Scivoletto et al. 2003) there are no published statistics on the life expectancy for such individuals in South Africa (Mothabeng 2011).

There were more male SCI participants (80\%) than female in this study. This is in line with a reported male to female ratio of 4:1 (Wyndaele \& Wyndaele 2006). Based on current literature, the male to female ratio of the incidence of SCI was found to be higher in less developed countries than in developed countries, probably because of the predominantly manual labour and greater risk taking behaviour of men in these countries (Ackery, Tator \& Krassioukov 2004; Draulans et al. 2011; Van den Berg et al. 2010).

The SCI participants had a mean BMI of $23.9 \mathrm{~kg} / \mathrm{m}^{2}$, which is within normal limits (WHO 2000). Body mass index values greater than $22 \mathrm{~kg} / \mathrm{m}^{2}$ are considered as high risk for obesity and obesity-related chronic diseases in the SCI population (Laughton et al. 2009). Obesity-related comorbidities may affect the endurance and mobility of people with SCI (Laughton et al. 2009).

Most of the SCI participants (58\%) were classified as ASIA D, with associated high sensory and motor scores. These high motor and sensory scores are expected to result in better gait efficiency because of the relationship between muscle strength and ambulatory capacity in SCI (Kim, Eng \& Whittaker 2004). Thus patients with ASIA D SCI have to be considered for gait re-education.

A large proportion $(46.7 \%)$ of the SCI participants presented with lesions above T10. The EE when walking is expected to be higher for this group. Kawashima et al. (2005) found that higher-level lesions resulted in higher EE in order to ambulate. Slower gait speed as a result of higher lesions result in excess load on the upper limb, making the gait less efficient (Kawashima et al. 2005).

Most of the SCI participants (38\%) reported less than 6 months since SCI. Motor recovery has been reported to take place mainly during the first 6 months after injury (Kirshblum et al. 2004). However, walking ability improvements have been reported for individuals with lesions more than 3 years after SCI (Harkema et al. 2012). This would suggest that poorer mobility may be expected in this study group as a result of the limited recovery time, as $60 \%$ of participants reported less than a year since SCI.

Some SCI participants (6.7\%) had no outpatient therapy after their initial inpatient rehabilitation and thus may not have reached their maximum functional capacity. Neurological recovery, including functional improvement in motor scores, and walking ability as a result of ongoing therapeutic intervention has been reported during the first and second year after injury (Burns et al. 2012). This would imply that once inpatient therapy has been concluded further recovery is still possible, which could be impeded by a lack of outpatient rehabilitation for the $6.7 \%$ of SCI participants in this study. In ideal circumstances the length of stay is determined by degree of motor recovery and potential for ambulation as well as patient goals. The majority of patients with SCI are discharged from hospital without having reached functional independence (Hastings, Ntsiea \& Olorunju 2015). This may be ascribed to limited funding and resources (availability of beds in rehabilitation units), which is largely the determining factor of length of stay (Mothabeng 2011).

Mean EE/m of SCI participants was four times higher than that of able-bodied participants $(p<0.001)$ (Table 3$)$. This is lower than the results reported by Kawashima et al. (2006), who found EE to be approximately six times higher for SCI participants who walk with orthotic-assisted gait than for able-bodied participants. However, in Kawashima's study, the SCI participants used the reciprocating gait orthotics and had complete paraplegia between $\mathrm{T} 5$ and T12, which may have contributed to higher EE. In this study, incomplete SCI lesions were included and a variety of assistive devices used to aid walking. The higher EE for SCI participants compared to able-bodied individuals can be attributed to greater upper limb and trunk involvement during walking in order to swing their paralysed lower limbs and maintain balance (Kawashima et al. 2006). Thus it is not surprising that ambulatory EE is significantly greater for SCI participants than for able-bodied participants. This indicates the need for provision of appropriate assistive devices to improve walking pattern and make walking energy efficient for people with SCI.

The EE for the able-bodied individuals was higher when distance was not taken into consideration. It is reported that walking velocity in people with SCI is slower than in the able-bodied population (Ditunno et al. 2007). The current study has shown that with a unit decrease in velocity the $\mathrm{EE} / \mathrm{m}$ increase by 0.41 (Table 5 ). The mean distance covered in the 6MWT for the SCI sample in this study was $114.10 \mathrm{~m}$ (SD \pm 104.40$)$ compared to $338.70 \mathrm{~m}(\mathrm{SD} \pm 67.20)$ for the ablebodied sample $(p<0.001)$. Thus the able-bodied individuals would have expended more energy than the SCI individuals to cover this distance. Energy expenditure per metre was much higher for the SCI participants than for able-bodied participants, indicating that the distance resulted in more EE for able-bodied individuals. 
Energy expenditure when walking with crutches was $0.34 \mathrm{cal} / \mathrm{m}$ less than when using a walking frame $(p=0.03)$. These findings are similar to the results reported by Ulkar et al. (2003), who also found crutches to be more energy efficient than walkers. However, in that study, the participants walked with both assistive devices in turn to control for differences in the two groups. Walking with a walking frame and an orthotic yielded the highest EE value of all the assistive devices in this study, with a mean of $0.54 \mathrm{cal} / \mathrm{m}$. The able-bodied participants yielded EE $/ \mathrm{m}$ of $0.08 \mathrm{cal} / \mathrm{m}$, thus the walking frame and orthotic group required 6.75 times the energy of the able-bodied group. Similar results were found by Kawashima et al. (2006), who reported that orthotic-assisted SCI gait required six times the energy cost during walking compared to able-bodied gait. The high EE cost of walking frame ambulation could be ascribed to slow walking speed, step-to-gait pattern and the repeated lifting of the frame necessary for forward motion (Priebe \& Kram 2011).

In the correlation analysis, overall inverse relationship was observed between EE/m and the following: hip flexion, hip extension, knee flexion ROM and velocity. Kawashima et al. (2006) also established that hip ROM affects the EE whilst walking. Higher thoracic lesions and resultant increased paralysis in the trunk and hip musculature produce smaller $\mathrm{ROM}$ at the hips during walking. Insufficient leg swing is therefore produced, which leads to slower gait speed, shorter distances and higher EE. Ability to flex the knee has also been found to contribute to a reduction in energy consumption during walking (Baardman et al. 2002). This indicates the need to maintain or improve knee flexion ROM during rehabilitation of patients with SCI.

Velocity and EE during walking yielded a significant inverse relationship. Walking velocity in people with SCI is slower than in the able-bodied population and they often require assistive devices (Ditunno et al. 2007; Van Hedel \& EMSCI Study Group 2009). SCI participants with an ASIA A classification walked at a mean velocity of $0.05 \mathrm{~m} / \mathrm{s}$ and utilised $0.71 \mathrm{cal} / \mathrm{m}$ whilst walking. Participants with an ASIA D classification walked at $0.38 \mathrm{~m} / \mathrm{s}$ and their $\mathrm{EE}$ was $0.26 \mathrm{cal} / \mathrm{m}$, indicating that ASIA D participants walk faster but with less EE.

Energy expenditure per metre decreased from ASIA A to ASIA D. Participants with an ASIA B classification had lower $\mathrm{EE} / \mathrm{m}$ than any of the other categories; however, this category consisted of one individual only, which could explain the skewed data. The differences in EE between different ASIA classifications can be explained by the fact that walking function regained after a SCI depends strongly on the level and completeness of the injury (Van Hedel \& Dietz 2010).

\section{Conclusion}

There are significant differences for EE whilst walking between the able-bodied and SCI populations. Factors to consider in order to maximise energy efficiency whilst walking are hip flexion ROM, walking velocity, and encouraging continued therapy beyond inpatient rehabilitation. Selection of a walking device that optimises EE whilst walking should be considered when clinically relevant.

\section{Limitations of the study}

The walking aids and orthotics used during the assessment were those that the participant usually used for walking. However, there is quite a difference in resources between rehabilitation units. Where knee extension was absent, some participants had callipers to compensate, whereas some from poorly resourced rehabilitation units only had backslabs and bandages to secure to the participant leg. Furthermore, a lack of ankle dorsiflexion to achieve swingthrough is compensated by an ankle foot orthotic (carbon or plastic), which was not available to some of the participants from poorly resourced rehabilitation units. This causes circumduction during gait, with potential balance, trunk and upper limb loading, which may increase EE.

\section{Acknowledgements Competing interests}

The authors declare that they have no financial or personal relationships which may have inappropriately influenced them in writing this article.

\section{Authors' contributions}

All three authors - J.V., M.V.N. and P.B. - were responsible for conception and design of the study. J.V. was responsible for acquisition of data. J.V., M.V.N. and P.B. did analysis and interpretation of data. M.V.N. drafted the manuscript and was responsible for revision of the manuscript. All three authors were responsible for final approval of the manuscript.

\section{References}

Ackery, A., Tator, C. \& Krassioukov, A., 2004, 'A global perspective on spinal cord injury', Epidemiology Journal of Neurotrauma 21, 1355-1370.

American Spinal Injury Association (ASIA), 2002, International standards for neurological classification of spinal cord injury, rev. edn, American Spinal Injury Association, Chicago, IL.

Arazpour, M., Bani, M.A., Hutchins, S.W. \& Jones, R.K., 2012, 'The physiological cost index of walking with mechanical and powered gait orthosis in patients with
spinal cord injury', Spinal Cord 51(5), 356-359, http://dx.doi.org/10.1038/ sc.2012.162

Baardman, G., ljzerman, J., Hermens, H., Veltink, P., Boom, H.B.K. \& Zilvold, G., 2002 'Knee flexion during the swing phase of orthotic gait: Influence on kinematics, kinetics and energy consumption in two paraplegic cases', Saudi Journal of Disability Rehabilitation 8, 20-32.

Burns, A.S., Marino, R.J., Flanders, A.E. \& Flett, H., 2012, 'Clinical diagnosis and prognosis following spinal cord injury', Handbook of Clinical Neurology 109, prognosis

Ditunno, J.F., Barbeau, H., Dobkin, B.H., Elashoff, R., Harkema, S. \& Marino, R.J., 2007, 'Validity of the walking scale for spinal cord injury and other domains of function in a multicenter clinical trial', Neurorehabilitation and Neural Repair 21, 539-550.

Draulans, N., Kiekens, C., Roels, E. \& Peers, K., 2011, 'Etiology of spinal cord injuries in Sub-Saharan Africa', Spinal Cord 49, 1148-1154.

Eriks-Hoogland, I.E., De Groot, S., Post, M.W. \& Van der Woude, L.H., 2011, 'Correlation of shoulder range of motion limitations at discharge with limitations in activities and participation one year later in persons with spinal cord injury', Journal of Rehabilitation Medicine 43, 210-215.

Field-Fote, E.C. \& Fluet, G.G., 2001, 'The spinal cord injury functional ambulation inventory (SCI-FAI)', Journal of Rehabilitation Medicine 33, 177-181. 
Hale, L., Williams, K., Ashton, C., Connole, T., McDowell, H. \& Taylor, C., 2007, 'Reliability of RT3 accelerometer for measuring mobility in people with multiple sclerosis: Pilot study', Journal of Rehabilitation Research and Development 44, 619-628.

Harkema, S.J., Schmidt-Read, M., Lorenz, D.J., Edgerton, V.R. \& Behrman, A.L., 2012 'Balance and ambulation improvements in individuals with chronic incomplete spinal cord injury using locomotor training-based rehabilitation', Archives of Physical Medicine and Rehabilitation 93, 1508-1517.

Hastings, B.M., Ntsiea, M.V. \& Olorunju, S., 2015, 'Factors that influence functiona ability in individuals with spinal cord injury: A cross sectional, observational study', South African Journal of Physiotherapy 71(1), 7. http://dx.doi.org/10.4102/ sajp.v71i1.235

Hendrick, P., Boyd, T., Low, O., Takarangi, K., Paterson, M., Claydon, L. \& Milsavljevic, S., 2010, 'Construct validity or RT3 accelerometer: A comparison of level-ground and treadmill walking at self-selected speeds', Journal of Rehabilitation Research and Development 47, 147-168.

Jackson, A.B., Carnel, C.T., Ditunno, J.F., Read, M., Boninger, M.L., Schmeler, M.R. et al., 2008 , 'Outcome measures for gait and ambulation in the spinal cord population', Journal of Spinal Cord Medicine 31, 487-499.

Joseph, C., Delcarme, A., Vlok, I., Wahman, K., Phillips, J. \& Nilsson, W.L., 2015 'Incidence and aetiology of traumatic spinal cord injury in Cape Town, South Africa: A prospective, population-based study', Spinal Cord 53(9), 692-696.

Kakebeeke, T.H., Lechner, H., Baumberger, M., Denoth, J., Michel, D. \& Knecht, H., 2002 , 'The importance of posture on the isokinetic assessment of spasticity', Spinal Cord 40, 236-243.

Kawashima, N., Nozaki, D., Abe, M.O., Akai, M. \& Nakazawa, K., 2005, 'Alternate leg movement amplifies locomotor-like muscle activity in spinal cord injured persons', Journal of Neurophysiology 93, 777-785.

Kawashima, N., Taguchi, D., Nakazawa, K. \& Akai, M., 2006, 'Effect of lesion level on the orthotic gait performance in individuals with complete paraplegia', Spina Cord 44, 487-494.

Kennedy, P., Evans, M.J., Berry, C. \& Mullin, J., 2003, 'Comparative analysis of goa achievement during rehabilitation for older and younger adults with spinal cord injury', Spinal Cord 41, 44-52.

Kim, C.M., Eng, J.J. \& Whittaker, M.W., 2004, 'Level walking and ambulatory capacity in persons with incomplete spinal cord injury: Relationship with muscle strength' Spinal Cord 42, 156-162.

Kirshblum, S., Millis, S., McKinley, W. \& Tulsky, D., 2004, 'Late neurologic recovery after traumatic spinal cord injury', Archives of Physical Medicine and Rehabilitation 85 1811-1817.

Kuo, A.D., 2007, 'The six determinants of gait and the inverted pendulum analogy: A dynamic walking perspective', Human Movement Science 26, 617-651.

Lammertse, D., Tuszynski, M.H., Steeves, J.D., Curt, A., Fawcett, J.W., Rask, C. et al., 2007, 'Guidelines for the conduct of clinical trials for spinal cord injury as developed by the ICCP panel: Clinical trial design', Spinal Cord 45, 232-242.

Laughton, G.E., Buchholz, A.C., Ginis, K.A.M. \& Goy, R.E., 2009, 'Lowering body mass index cutoffs better identifies obese persons with spinal cord injury', Spinal Cord $47,757-762$.
Mahoney, J.S., Engebretson, J.C., Cook, K.F., Hart, K.A., Robinson-Whelen, S. \& Sherwood, A.M., 2007, 'Spasticity experience domains in persons with spinal cord injury', Archives of Physical Medicine and Rehabilitation 88, 287-294.

McKinley, W., Santos, K., Meade, M. \& Brooke, K., 2007, 'Incidence and outcomes of spinal cord injury clinical syndromes', Journal of Spinal Cord Medicine 30(3), 215-224.

Mothabeng, D.J., 2011, 'Participation for people living with spinal cord injury in the Tshwane metropolitan area', PhD thesis, Department of Physiotherapy, University of Pretoria, viewed 14 April 2015, from http://upetd.up.ac.za/thesis/available/ etd-07212011-132739/unrestricted/00front.pdf

Priebe, J.R. \& Kram, R., 2011, 'Why is walker-assisted gait metabolically expensive?', Gait Posture 34, 265-269.

Richards, J.S., Waites, K., Chen, Y.Y., Kogus, S. \& Schmitt, M.M., 2004, ‘The epidemiology of secondary conditions following spinal cord injury', Topics in Spinal Cord Injury Rehabilitation 10, 15-29.

Scivoletto, G., Morganti, B., Ditunno, P., Ditunno, J.F. \& Molinari, M., 2003, 'Effects on age on spinal cord lesion patients' rehabilitation', Spinal Cord 41, 457-464.

Scivoletto, G., Romanelli, A., Mariotti, A., Marinucci, D., Tamburella, F., Mammone, A. et al., 2008, 'Clinical factors that affect walking level and performance in chronic spinal cord lesion patients', Spine 33, 259-264.

Stuart, R.N., Holland, A.E. \& New, P.W., 2009, 'Walking ability at discharge from inpatient rehabilitation in a cohort of non-traumatic spinal cord injury patients', Spinal Cord 47, 763-768.

Ulkar, B., Yavuzer, G., Guner, R. \& Ergin, S., 2003, 'Energy expenditure of the paraplegic gait: Comparison between different walking aids and normal subjects', International Journal of Rehabilitation Research 26, 213-217.

Van Cauwenberghe, E., Gubbels, J., De Bourdeaudhuij, I. \& Cardon, G., 2011 'Feasibility and validity of accelerometer measurements to assess physical activity in toddlers', International Journal of Behavioral Nutrition and Physical Activity 8 , 67-78.

Van den Berg, M.E., Castellote, J.M., Mahillo-Fernandez, I. \& De Pedro-Cuesta, J. 2010, 'Incidence of spinal cord injury worldwide: A systematic review', Neuroepidemiology 34, 184-192.

Van Hedel, H.J. \& Dietz, V., 2010, 'Rehabilitation of locomotion after spinal cord injury', Restorative Neurology and Neuroscience 28, 123-134.

Van Hedel, H.J. \& EMSCl Study Group, 2009, 'Gait speed in relation to categories of functional ambulation after spinal cord injury', Neurorehabilitation and Neural Repair 23, 343-350.

World Bank, 2009, The World Bank annual report 2009, viewed 14 April 2015, from http:// siteresources.worldbank.org/EXTAR2009/Resources/6223977-1252950831873/ AR09_Complete.pdf

World Health Organization (WHO), 2000, Obesity: Preventing and managing the global epidemic, World Health Organization, Technical Report 894.

Wyndaele, M. \& Wyndaele, J.J., 2006, 'Incidence, prevalence and epidemiology of spinal cord injury: What learns a worldwide literature survey?', Spinal Cord 44, 523-529.

Yamakawa, K., Tsal, C.K., Haig, A.J., Miner, J.A. \& Harris, M.J., 2004, 'Relationship between ambulation and obesity in older persons with and without low back pain', International Journal of Obesity 28, 137-143. 